\title{
SOBREVIVÊNCIA E CRESCIMENTO DE CINCO ESPÉCIES DO CERRADO EM DIFERENTES ADUBAÇÕES NA RECUPERAÇÃO DE UMA CASCALHEIRA, DIAMANTINA-MG
}

Aline Cristina de Almeida ${ }^{1}$, Israel Marinho Pereira ${ }^{2}$, Michele Aparecida Pereira da Silva $^{3}$, Leandro Carlos ${ }^{4}$, Filipe Martins de Souza ${ }^{5}$,

${ }^{1}$ Engenheira Agrônoma pela Universidade Federal dos Vales do Jequitinhonha e Mucuri, alinecrit@gmail.com

${ }^{2}$ Doutor da Universidade Federal dos Vales do Jequitinhonha e Mucuri

${ }^{3}$ Pós-doutoranda da Universidade Federal dos Vales do Jequitinhonha e Mucuri

${ }^{4}$ Doutor do Instituto Federal Goiano,

${ }^{5}$ Engenheiro Florestal pela Universidade Federal dos Vales do Jequitinhonha e Mucuri

Recebido em: 08/04/2016 - Aprovado em: 30/05/2016 - Publicado em: 20/06/2016 DOI: 10.18677/Enciclopedia_Biosfera_2016_108

\section{RESUMO}

Dentre as várias atividades antrópicas, a mineração tem sido considerada como uma das que mais provocam significativos danos ou até mesmo impactos irreversíveis ao meio ambiente. O plantio de mudas de espécies arbóreas é a técnica de recuperação de áreas degradadas mais utilizado no Brasil em áreas impactadas pela mineração, porém, diante da baixa fertilidade dos substratos resultantes desse processo, faz-se necessário o uso de uma adubação no momento do plantio. Dessa forma, objetivou-se avaliar a sobrevivência, incremento em altura e diâmetro de cinco espécies nativas do cerrado na recuperação de uma cascalheira, sob a influência de combinações de adubação. $O$ experimento foi implantado em delineamento inteiramente ao acaso (DIC) em sistema fatorial $8 \times 5$ (oito adubações e cinco espécies). Os resultados indicaram que não houve diferença entre os tratamentos para sobrevivência. Para a variável incremento em diâmetro, constatouse que o tratamento T8 (adubação orgânica) foi superior aos demais. A espécie Eremanthus erythropappus foi a que obteve maiores incrementos em altura e diâmetro, porém maiores índices de mortalidade enquanto que as espécies Hymenaea courbaril e Tibouchina candolleana obtiveram os maiores índices de sobrevivência na avaliação entre espécies. Permitindo concluir com o trabalho que a adubação com calcário influencia positivamente a sobrevivência das espécies avaliadas e que estas apresentam maior diâmetro médio com adubação orgânica.

PALAVRAS-CHAVE: Mineração, reflorestamento, restauração.

\section{SURVIVAL AND GROWTH OF SPECIES IN FIVE DIFFERENT FERTILIZATIONS LEVELS IN THE RECOVERY OF A GRAVEL PIT, DIAMANTINA-MG}

\section{ABSTRACT}

Among the various human activities, mining has been considered as one of the most significant cause damage or even irreversible environmental impacts. The planting of tree species seedlings is the degraded areas recovery technique most used in Brazil in areas impacted by mining, however, given the low fertility of the substrates 
resulting from this process, it is necessary to use a fertilizer at planting. Thus, aimed to evaluate the survival, growth in height and diameter of five native species of the Cerrado in the recovery of a gravel pit, under the influence of fertilizer combinations. The experiment was carried out in a completely randomized design (CRD) factorial system $8 \times 5$ (eight fertilizations and five species). The results showed no difference between treatments for survival. For the variable increment in diameter, it was found that the T8 treatment (organic fertilization) was superior. The species Eremanthus erythropappus was the one with greater increases in height and diameter, but higher mortality rates while Hymenaea courbaril species and Tibouchina candolleana had the highest survival rates in the evaluation of species. Allowing complete the work that fertilization with limestone positively influences the survival of species assessed and that these had higher mean diameter in the treatment with organic fertilizer.

KEYWORDS: mining, reforestation, restoration.

\section{INTRODUÇÃO}

As atividades antrópicas realizadas de forma não planejada têm provocado um aumento na extensão e na intensidade das áreas degradadas mundialmente. No processo de exploração de cascalho geralmente são utilizadas máquinas pesadas e com a presença de um trafego intenso de veículos há compactação do solo e perda da resiliência do local, sendo necessário o plantio de mudas no processo de estabelecimento da cobertura vegetal (FERREIRA, 2010).

Os principais problemas encontrados nas áreas degradadas pela atividade de mineração são a compactação do material exposto que resulta em baixa taxa de infiltração e incapacidade de armazenamento de água (LONGO et al., 2005). A perda da capacidade de se recuperar sem intervenção humana é resultante da perda do banco de sementes devido a ação de decapeamento do solo da área minerada. Com isso há um aumento do risco de erosão ao solo já que o substrato resultante deste processo encontra-se bastante susceptível e exposto diante da ausência da cobertura vegetal.

A extração do cascalho gera impactos de diversas magnitudes, tendo o início com a supressão tanto da vegetação quanto na qualidade do solo, o que resulta na perda da resiliência (NETO et al., 2014), e em muitos casos em impactos ambientais irreversíveis (BRANDT, 1998), resultando na perda da biodiversidade, fertilidade dos solos, aumento da poluição visual e, no desequilíbrio entre os ecossistemas (FERNANDES \& PESSÔA, 2011). Assim, é necessária a intervenção do homem para mitigar tais impactos.

No Brasil, o método mais comum de reflorestamento é a regeneração artificial por meio do plantio de mudas. O reflorestamento é entendido como a atividade dedicada a recompor a vegetação de uma área mediante o estabelecimento de uma cobertura vegetal e tradicionalmente projetos de recuperação priorizam o plantio de espécies arbóreas (GANEM, 2009). Além disso, a introdução de espécies arbóreas pode melhorar as propriedades físicas, químicas e microbiológicas do solo e proporcionar as mais estreitas e complexas relações entre solo-planta-animal (CARDOSO et al., 2011).

Os principais desafios enfrentados na recuperação de terras severamente degradadas são na gestão dos sistemas e a descoberta de espécies de plantas que crescerão sob as duras condições comuns em solos degradados (CHAER et al., 2011). É importante conhecer os diferentes comportamentos em relação à 
sobrevivência e desenvolvimento inicial das plantas estudadas permitindo fornecer informações na escolha destas em trabalhos de recuperação de áreas degradadas (SANTOS et al., 2012). Dessa forma, instituições de pesquisas, órgãos ambientais e diversos segmentos da sociedade, têm procurado nas últimas décadas por alternativas ecologicamente corretas para mitigar os impactos ambientais negativos dessas ações antrópicas (DUARTE et al., 2011) e reproduzir o padrão natural das comunidades vegetais para elevar a margem de sucesso na recuperação ambiental (OLIVEIRA et al., 2015).

Diante do exposto, objetivou-se avaliar se o incremento em altura, diâmetro e sobrevivência de cinco espécies nativas do cerrado foi influenciado pelas combinações de adubação submetidas, em uma área de cascalheira, no Parque Estadual do Biribiri em Diamantina-MG.

\section{MATERIAL E MÉTODOS}

O experimento foi implantado e conduzido em uma área de cascalheira com cerca de dez hectares, situada no Parque Estadual do Biribiri (PEB), região do Alto Jequitinhonha, no Complexo da Serra do Espinhaço, entre as coordenadas 0649511,86 e 649640,24 m de longitude e 7987114,81 e 7987250,62 m de latitude (UTM) e altitude média de $1412 \mathrm{~m}$.

A degradação da cascalheira ocorreu em virtude da mineração de cascalho para ser usado na construção da rodovia BR-367 em meados da década de 50 do século XX. Após esse período, a extração de cascalho continuou sendo utilizada para obras civis pelo município de Diamantina.

No entorno da cascalheira verifica-se a ocorrência de vegetação típica de Campo Rupestre, Cerrado Campestre, Floresta Semidecidual e Candeal. Os solos predominantes na área em estudo antes da extração de cascalho foram caracterizados como Plintossolos, constituídos por material mineral, apresentando horizonte plíntico ou litoplíntico iniciando dentro de $40 \mathrm{~cm}$, ou dentro de $200 \mathrm{~cm}$ quando imediatamente abaixo do horizonte $A$ ou $E$, ou de outro horizonte que apresente cores pálidas, variegadas ou com mosqueados em quantidade abundante (EMPRAPA, 2006).

O substrato do local antes da implantação do experimento encontrava-se totalmente descoberto de vegetação e com grande compactação basicamente por rochas e com sulcos de erosão profundos, baixos teores de matéria orgânica e baixa capacidade de armazenamento de água (Tabela 1).

TABELA 1: Análise química de solo proveniente da cascalheira na profundidade de $0-20 \mathrm{~cm}$ do solo.

\begin{tabular}{|c|c|c|c|c|c|c|}
\hline \multirow[t]{2}{*}{$\mathrm{pH}$} & $\mathrm{P} \quad \mathrm{K}$ & $\mathrm{Ca} \mathrm{Mg} \mathrm{Al} \mathrm{H}+\mathrm{Al}$ & SB $\mathrm{MO}$ & $\begin{array}{c}\mathrm{t} \\
0,92\end{array}$ & $\begin{array}{c}\mathrm{T} \\
3,35\end{array}$ & $\begin{array}{cc}\mathrm{m} & \mathrm{V}(\%) \\
(\%) & \\
& 24 \\
13 & \\
\end{array}$ \\
\hline & -- $\mathrm{mg} \mathrm{dm}^{-3}$ & -.- $\mathrm{cmol}_{\mathrm{c}} \mathrm{dm}^{-3}$ & ------- & Areia & $\begin{array}{r}\text { Argila } \\
-\mathrm{g} \mathrm{kg}^{-1}--\end{array}$ & Silte \\
\hline 5,75 & $2,3918,76$ & $0,550,20,12 \quad 2,55$ & $0,8 \quad 0,55$ & 80,5 & 11 & 8,5 \\
\hline
\end{tabular}


O regime climático da região é tipicamente subtropical, Cwb na classificação de Koppen, caracterizado por verões brandos e úmidos (outubro a abril) e invernos mais frescos e secos (junho a agosto). A precipitação média anual varia de $1.250 \mathrm{a}$ $1.550 \mathrm{~mm}$ e a temperatura média anual situa-se na faixa de $18^{\circ}$ a $19^{\circ} \mathrm{C}$, sendo predominantemente amenas durante todo $O$ ano, devido às superfícies mais elevadas dessa serra. A umidade relativa do ar é elevada, atingindo médias anuais de 75,6\% (NEVES et al., 2005).

Antes da realização do plantio foi aplicada uma camada de aproximadamente $20 \mathrm{~cm}$ de topsoil oriundos de uma área limítrofe do parque, denominada de Campus Juscelino Kubitschek da Universidade Federal dos Vales do Jequitinhonha e Mucuri (UFVJM). O solo da área doadora foi classificado como Neossolo Quartzarênico, apresentando textura de areia ou areia franca até no mínimo, a profundidade de 150 $\mathrm{cm}$ a partir da superfície ou até o contato lítico, com teor de argila inferior a 15\% (EMBRAPA, 2006).

O experimento foi implantado em delineamento inteiramente ao acaso (DIC), em fatorial $8 \times 5$ (oito adubações e cinco espécies), com três parcelas e três repetições. Utilizaram-se cinco espécies do cerrado listadas na Tabela 2, com ocorrência em áreas adjacentes. O plantio de mudas foi realizado em fevereiro de 2011 e posterior ao controle de ervas daninhas. Os tratamentos de adubação consistiram nas seguintes adubações:

T1: testemunha,

T2: adubação química, orgânica e aplicação de calcário,

T3: adubação química e orgânica,

T4: adubação química e aplicação de calcário,

T5: adubação química,

T6: adubação orgânica e aplicação de calcário,

T7: aplicação de calcário e

T8: adubação orgânica.

As combinações entre adubação química (150 gramas de 4-14-8 por cova), orgânica (3 litros de esterco bovino) e aplicação de calcário dolomítico (10 gramas por cova) em cada cova no plantio foram realizadas de forma aleatória em um espaçamento de $2 \times 2$, totalizando 360 covas de $30 \times 30 \times 30 \mathrm{~cm}$ de dimensões.

O critério para a escolha das espécies foi relacionado ao grupo sucessional que pertencem, visando obter uma rápida e boa cobertura inicial do solo, e minimizar a competição com herbáceas e gramíneas agressivas, além de criar um ambiente favorável para crescimento e sobrevivência dos indivíduos (MARCUZZO et al., 2015). 
QUADRO 1. Espécies utilizadas no experimento e suas principais características.

\begin{tabular}{|c|c|c|c|}
\hline Espécie & Nome Popular & Família & Habitat \\
\hline $\begin{array}{l}\text { Eremanthus } \\
\text { erythropappus } \\
\text { (DC.) Macleish }\end{array}$ & Candeia & Asteraceae & Áreas montano-campestre \\
\hline $\begin{array}{l}\text { Hymenaea } \\
\text { courbaril L. }\end{array}$ & Jatobá & Fabaceae & Ocorre em áreas bem drenadas. \\
\hline $\begin{array}{l}\text { Copaifera } \\
\text { langsdorffii Desf }\end{array}$ & Cobaíba & Fabaceae & $\begin{array}{l}\text { Ocorre em matas primárias e } \\
\text { formações secundárias. }\end{array}$ \\
\hline $\begin{array}{l}\text { Tibouchina } \\
\text { candolleana (Mart. } \\
\text { ex DC.) Cogn. }\end{array}$ & $\begin{array}{l}\text { Quaresmeira da } \\
\text { Serra }\end{array}$ & Melastomataceae & $\begin{array}{l}\text { Mata ciliar de regiões de altitudes } \\
\text { e em terrenos de meia encosta } \\
\text { em capões. }\end{array}$ \\
\hline $\begin{array}{l}\text { Aspidosperma } \\
\text { cylindrocarpon } \\
\text { Müll.Arg }\end{array}$ & $\begin{array}{l}\text { Pindaíba } \\
\text { Vermelha }\end{array}$ & Annonaceae & $\begin{array}{l}\text { Topos de morros em terrenos } \\
\text { arenosos bem drenados. }\end{array}$ \\
\hline
\end{tabular}

Fonte: LORENZI (2002).

As avaliações do crescimento das plantas no campo foram realizadas por meio de medições anuais, sendo o primeiro registro em maio de 2011 aos 90 dias após o plantio. Foi contabilizada a mortalidade das mudas e realizou-se o replantio das que estavam mortas. Todas as mudas foram identificadas com plaquetas de alumínio.

No período de 2011 a 2012, o índice pluviométrico da região foi considerado relativamente baixo devido a baixa ocorrência ou até mesmo a ausência de chuvas. No ano de 2011 a pluviosidade variou de 1 a 325 milímetros de chuva ocorrendo dias sem chuvas e no ano de 2012 variou de 1 a 360 milímetros de acordo com os dados do INMET.

Em agosto de 2013, as variáveis de incremento em altura $(\mathrm{cm})$, medida do nível do solo até a interseção da última gema, e o diâmetro do caule $(\mathrm{mm})$ ao nível do solo e sobrevivência (\%) foram avaliadas. Para a medição da altura total e do diâmetro do caule utilizou-se trena graduada e 0 paquímetro digital, respectivamente.

Para cada período avaliado foi calculado o incremento médio em altura e diâmetro, a fim de verificar em quais tratamentos ocorreu o maior desenvolvimento. Segundo PORTELA et al., (2001), o incremento foi expresso em:

$\mathbf{I}=\mathbf{X f}-\mathbf{X} \mathbf{i}$; sendo:

$\mathrm{I}=$ Incremento (no caso em altura e em diâmetro),

Xf = valor da variável (DAS ou ALT.) referente ao período final em que foram mensurados,

$\mathrm{X} \mathrm{i}=$ valor da variável (DAS ou $\mathrm{ALT}$.) referente ao período inicial em que foram mensurados.

Os dados de incremento em altura e diâmetro do colo, e sobrevivência, foram submetidos à analise de variância, e quando necessário, realizado o teste de média de Tukey a $95 \%$ de probabilidade.

\section{RESULTADOS E DISCUSSÃO}

Houve interações significativas entre os fatores para as variáveis altura e sobrevivência. Ao considerar 0 incremento médio em diâmetro, obtiveram-se diferenças nos tratamentos e entre espécies. A porcentagem de plantas sobreviventes ao final da avaliação atingiu $76,38 \%$ do total de indivíduos plantados. Segundo ALMEIDA \& SÁNCHEZ (2005), 10\% de mortalidade de mudas é 
considerado como referência em projetos de revegetação, embora os mesmos observassem em seus projetos $38 \%$ de mudas mortas em áreas mineradas no Estado de São Paulo.

As espécies Eremanthus erythropappus e Copaifera langsdorffii mostraram diferenças significativas para os tratamentos avaliados (Tabela 2). Para a $E$. erythropappus, o melhor tratamento foi o T6 (adubação orgânica e aplicação de calcário) com média de $55,55 \%$ de sobrevivência, e para $C$. langsdorffii os melhores tratamentos foram T1 (testemunha), T4 (adubação química e calcário), T7 (somente calcário) e T8 (adubação orgânica) com médias respectivamente de: 100, 88,88 e $100 \%$. As demais não diferiram entre os tratamentos avaliados. Espécies do Cerrado não se desenvolvem bem quando são adicionadas adubações químicas, já que estão adaptadas a condições de solo extremamente ácido (EMBRAPA, 1993).

Observou-se que Tibouchina candolleana e Hymenaea courbaril obtiveram os melhores índices de sobrevivência, sendo respectivamente de 98,61\% e 97,22\%. Por outro lado, observa-se que Eremanthus erythropappus obteve o menor índice, $20,83 \%$. Esse resultado pode ter sido resultante da competição com gramíneas como a Urochloa decumbens que apresenta uma elevada densidade na área em estudo. Fator este que pode ter intensificado a mortalidade para tal espécie na área de estudo, já que de acordo FELFILI et al. (2008), PILON \& DURIGAN (2013) a disponibilidade de luz, água, regime de temperatura e condições edáficas, influenciam no estabelecimento das mudas, assim como a falta dos tratos culturais necessários, como roçagem e coroamento das plantas.

A matocompetição condiciona fatores negativos ao crescimento, (LONDERO et al., 2012) e é um fator limitante à sobrevivência da maioria das espécies florestais (CARON et al., 2012) e principalmente das espécies pioneiras. Por outro lado, MELO et al. (2014) ao avaliarem a sobrevivência após aplicar doses crescentes de adubação orgânica também observaram um aumento de mortalidade de indivíduos destas espécies.

De acordo com um estudo feito por AMARAL et al. (2013) em uma área minerada no Parque Estadual do Biribiri, as famílias Asteraceae e Melastomataceae apresentam maior resistência à degradação do ambiente, favorecendo a colonização de espécies resistentes à baixa umidade, altos teores de areia, além de alta cobertura por cascalho exposto, a exemplo de Tibouchina candolleana. No entanto, observou-se um baixo percentual de sobrevivência de E. erythropappus (Tabela 2) praticamente em todos os tratamentos, exceto T6 (adubação orgânica e aplicação de calcário), o que pode ser explicado pelo surgimento de espécies herbáceas exóticas altamente competitivas (BRANQUINHO et al.,2013).

TABELA 2. Sobrevivência de espécies dentro de cada tratamento avaliado, sendo que Eremanthus erythropappus (E1), Tibouchina candolleana (E2), Aspisdosperma cylindrocarpon (E3), Copaifera langsdorffii (E4) Hymenaea courbaril (E5) e tratamento (trat), espécie (esp).

\begin{tabular}{|c|c|c|c|c|c|c|c|c|}
\hline & T1 & T2 & T3 & T4 & 16 & T7 & T8 & \\
\hline$\overline{\mathrm{E} 1}$ & $22 \mathrm{~b} \mathrm{~B}$ & $11 \mathrm{cB}$ & $11 \mathrm{cC}$ & $22 \mathrm{~b} \mathrm{~B}$ & 22 c C & $55 \mathrm{~b} \mathrm{~B}$ & $11 \mathrm{cB}$ & $11 \mathrm{cC}$ \\
\hline E2 & 100 a $A$ & 88 a A & 100 a $A$ & 100 a $A$ & 100 a $A$ & 100 a $A$ & 100 a $A$ & \\
\hline E3 & 77 a A & 88 a $A$ & 100 a $A$ & 88 a $A$ & 88 a $A$ & $77 \mathrm{ab} A$ & 100 a $A$ & $66 \mathrm{~b} \mathrm{~B}$ \\
\hline E4 & 100 a $A$ & $77 \mathrm{ab} A$ & $44 \mathrm{~b} \mathrm{~B}$ & 88 a $A$ & $44 \mathrm{~b} \mathrm{~B}$ & $77 \mathrm{ab} A$ & 100 a $A$ & 100 a $A$ \\
\hline E5 & 100 a $A$ & $11 \mathrm{cB}$ & 100 a $A$ & 100 a $A$ & 88 a $A$ & 100 a A & 100 a $A$ & 100 a $A$ \\
\hline
\end{tabular}

Médias seguidas da mesma letra maiúscula na coluna, não diferem estatisticamente entre si pelo teste de Tukey a 95\% de probabilidade ao comparar as espécies no tratamento e médias seguidas de mesma letra minúscula na linha não diferem entre si ao avaliar a espécie em cada tratamento. 
Para o incremento em altura, as espécies responderam de forma diferente às distintas adubações (Figura 1). O crescimento em altura de uma árvore é um bom indicador das condições em que foram plantadas (DELARMELINA, 2014). Assim, como a qualidade do sítio em que estas se encontram.

Ocorreu um decréscimo em altura na espécie $H$. courbaril na maioria dos tratamentos. Esse resultado pode estar relacionado com a morte da planta, soterramento, seca de ponteiro ou quaisquer condições adversas que ocorreram no local, como a perda do ramo principal (ponteiro), ocorrendo a rebrota. A média de incremento geral das mudas testadas no experimento foi de $4,13 \mathrm{~cm}$.

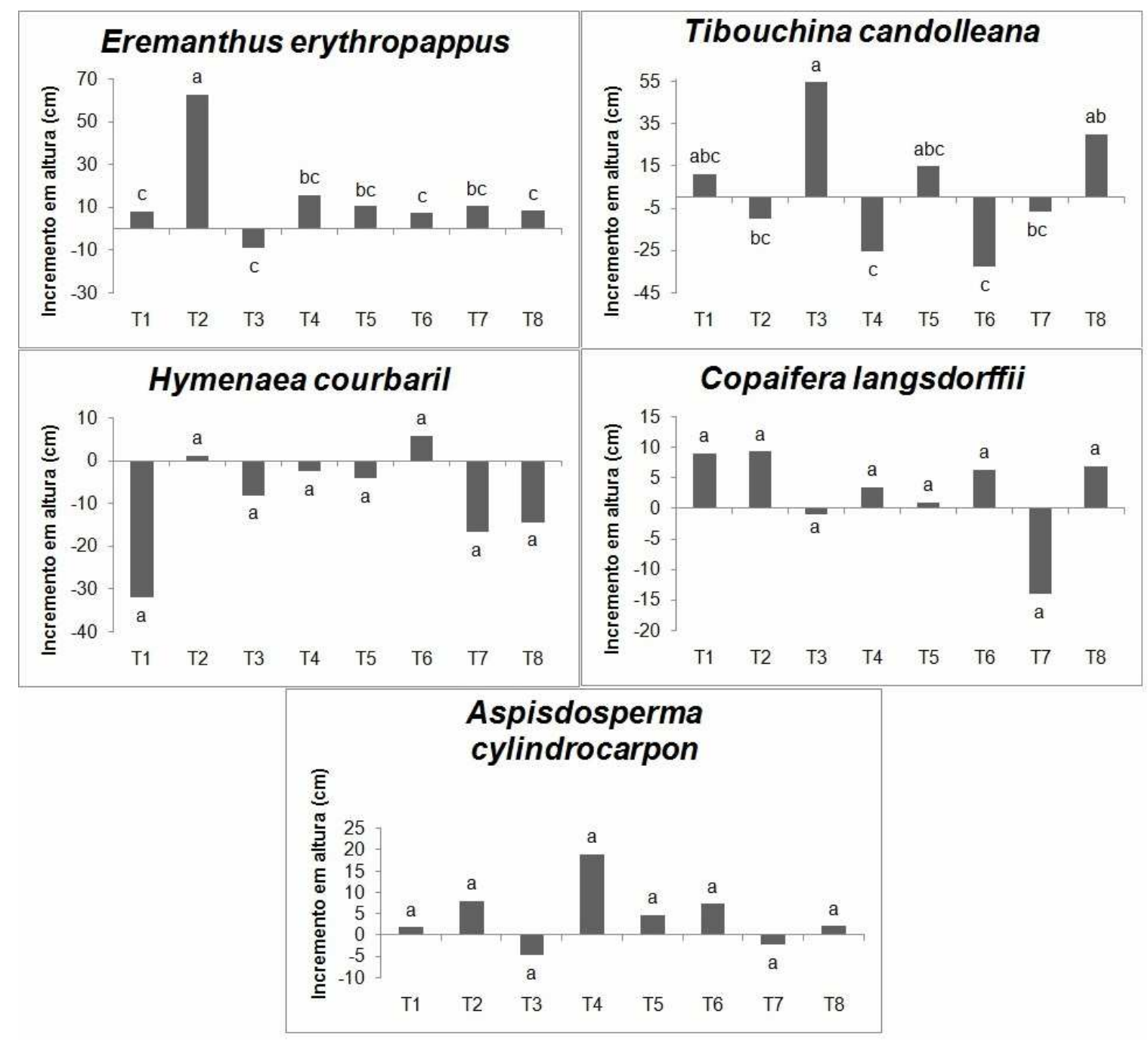

FIGURA 1. Incremento médio em altura das espécies avaliadas em diferentes tratamentos. Sendo que, T1: testemunha, T2: adubação química, orgânica e calcário, T3: adubação química e orgânica, T4: adubação química e calcário, T5: adubação química, T6: adubação orgânica e calcário, T7: somente calcário e T8: adubação orgânica.

Observou-se que E. erythropappus obteve um incremento máximo de $63 \mathrm{~cm}$ no T2 (adubação química, orgânica e aplicação de calcário) e, T. candolleana com incremento de $54 \mathrm{~cm}$ no T3 (adubação química e orgânica), ambas com a presença de adubação orgânica e química. Estas adubações melhoram a fertilidade do ENCICLOPÉDIA BIOSFERA, Centro Científico Conhecer - Goiânia, v.13 n.23; p. $1711 \quad 2016$ 
substrato e aumentam a disponibilidade de nutrientes as plantas, respectivamente. As demais espécies não apresentaram diferenças dentre os tratamentos aplicados.

Não houve interação entre as adubações e as espécies em relação ao incremento em diâmetro. Eremanthus erythropappus obteve um maior incremento médio em diâmetro de $1,93 \mathrm{~mm}$, já $H$. courbaril apresentou um decréscimo médio de -0,53 mm (Figura 2), o que pode ser explicado pela seca de ponteiro registrada para a espécie. Assim como neste estudo, $H$. courbaril também apresentou baixos valores de incremento em diâmetro no Distrito Federal, em área de cerrado (OLIVEIRA et al., 2015).

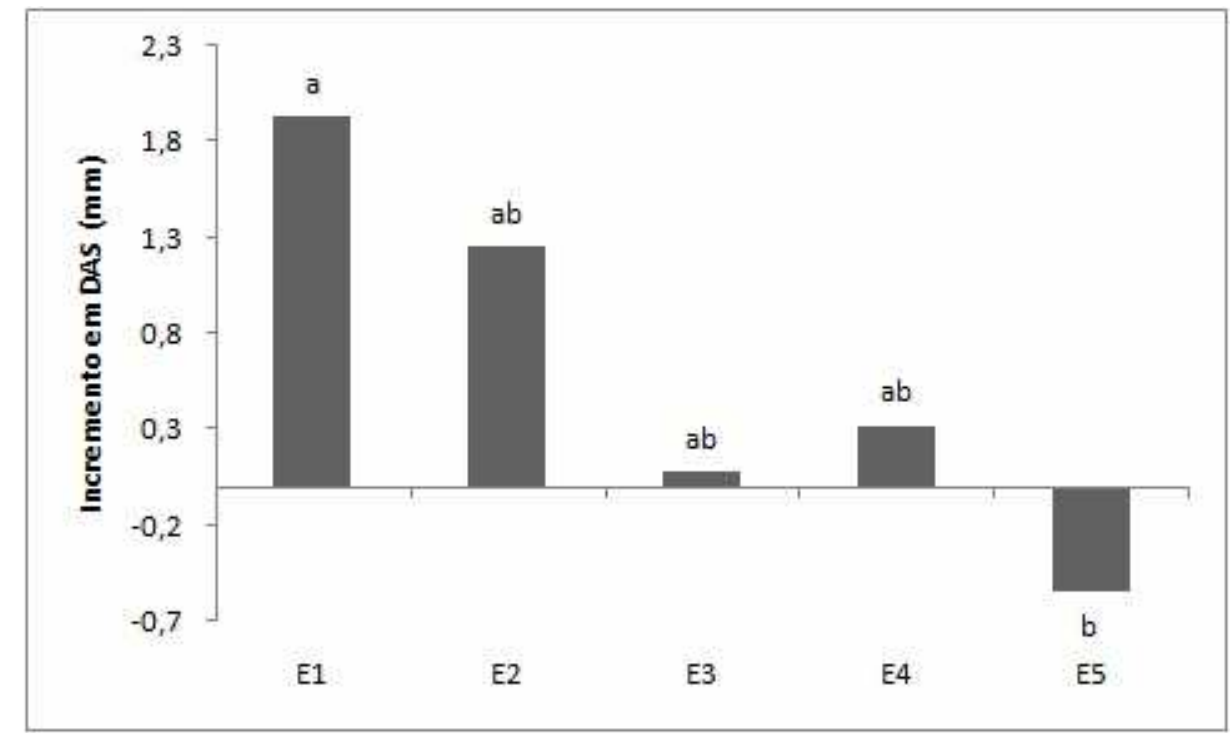

FIGURA 2. Incremento médio em diâmetro nas espécies avaliadas. Sendo: Eremanthus erythropappus (E1), Tibouchina candolleana (E2), Aspisdosperma cylindrocarpon (E3), Copaifera langsdorffii (E4) eHymenaea courbaril (E5).

A média geral de incremento em diâmetro das mudas no experimento foi de $0,60 \mathrm{~mm}$. Os oitos tratamentos testados apresentaram diferenças entre si, sendo o tratamento T8 (adubação orgânica) superior com média de 2,90 mm comparada aos demais. É importante ressaltar que o tratamento T6 (adubação orgânica e aplicação de calcário) foi o que proporcionou o menor incremento com média de $-0,91 \mathrm{~mm}$ (Figura 3).

Segundo DUARTE et al. (2015), para várias espécies florestais nativas, se obtém resultados positivos à fertilização e as maiores respostas são de espécies com maiores taxas de crescimento, independentemente do grupo sucessional. Além disso, a introdução de espécies arbóreas pode melhorar as propriedades físicas, químicas (CARDOSO, 2011) e fornecer um ambiente propicio para o desenvolvimento destas. 


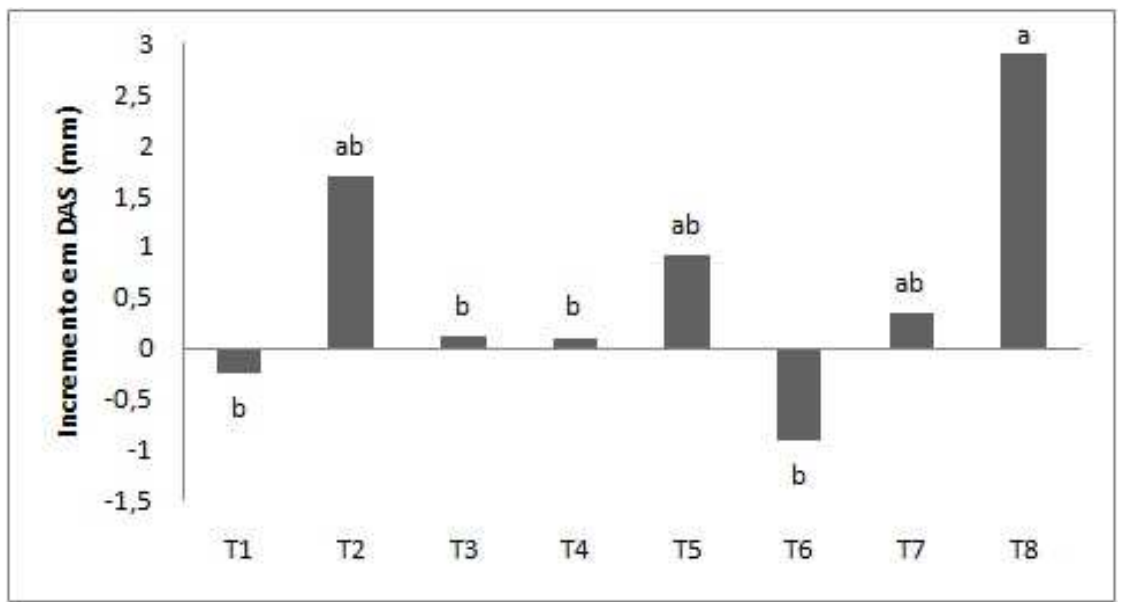

FIGURA 3. Incremento médio em diâmetro nos diferentes tratamentos, sendo que, T1: testemunha, T2: adubação química, orgânica e aplicação de calcário, T3: adubação química e orgânica, T4: adubação química e calcário, T5: adubação química, T6: adubação orgânica e calcário, T7: somente calcário e T8: adubação orgânica.

\section{CONCLUSÃO}

As espécies Eremanthus erythropappus, Tibouchina candolleana, Aspisdosperma cylindrocarpon, ,Copaifera langsdorffii e Hymenaea courbaril têm uso potencial em programas de recuperação de cascalheiras. adubação.

As diferentes espécies possuem demandas diferentes em relação à

A adubação com calcário influencia positivamente a sobrevivência das espécies avaliadas e estas apresentam maior diâmetro médio com adubação orgânica.

\section{REFERÊNCIAS}

ALMEIDA, R. O. P.; SÁNCHEZ, L. E. Revegetação de áreas de mineração: critérios de monitoramento e avaliação do desempenho. Revista Árvore, v.29, n.1,p.47-54, 2005. Disponível em :<http://dx.doi.org/10.1590/S0100-67622005000100006> doi: $10.1590 / \mathrm{S} 0100-67622005000100006$

AMARAL, W. G.; PEREIRA, I. M ; MACHADO, E. L. M. ; Oliveira, P.A ; DIAS, L. G. ; AMARAL, C. S. . Relação das espécies colonizadoras com as características do substrato em áreas degradadas na serra do espinhaço meridional. Bioscience Journal, v. 29, n.5, p. 1941-1951, 2013.

BRANDT, W. Avaliação de cenários em planos de fechamento de minas. DIAS, L. E.; MELLO, J. W. V. (Ed.) Recuperação de áreas degradadas. Viçosa: UFV/Departamento de Solos/Sociedade Brasileira de Recuperação de Áreas Degradadas, p. 131-134,1998.

BRANQUINHO, F. G. G.; BARBOSA, G. P. ; PEREIRA, I. M. ; CARVALHO, T. F. . ENCICLOPÉDIA BIOSFERA, Centro Científico Conhecer - Goiânia, v.13 n.23; p. 1713 
Regeneração natural em cascalheira em recuperação por meio do uso de topsoil. Enciclopédia Biosfera, v. 9, n.17, p. 2297-2305, 2013.

CARDOSO, E.L.; NAVES SILVA, M.L.; Curi, N.; FERREIRA, M. M.; FREITAS, D. A. F.; Qualidade química e física do solo sob vegetação arbórea nativa e pastagens no pantanal sul-mato-grossense, Revista Brasileira de Ciência do Solo, v.35, n 2, , p.613-622, 2011.

CARON, B. O. ;LAMEGO, F. P. ; SOUZA,V. Q. ; COSTA, E. C. ; ELOY, E. ; BEHLING, A. ;TREVISAN, R. Interceptação da radiação luminosa pelo dossel de espécies florestais e sua relação com o manejo das plantas daninhas.Ciência Rural, v.42, n.1, p. 75-82, 2012. Disponível em <http://dx.doi.org/10.1590/S010384782012000100013> doi: 10.1590/S0103-84782012000100013

CHAER, G. M. ; RESENDE, A. S. ; CAMPELLO, E. F. C. ; de FARIA, S. M. ; BODDEY, R. M. SCHMIDT, S.. Nitrogen-fixing legume tree species for the reclamation of severely degraded lands in Brazil. Revista Tree Physiology, v. 31, n. 2 p.139-149, $2011 . \quad$ Disponível< http://treephys.oxfordjournals.org/content/31/2/139.short> doi: 10.1093/treephys/tpq116

DELARMELINA, W. M.; CALDEIRA, M. V. W. ; FARIA, J. C. T. ; GONCALVES, E. O. ; ROCHA, R. L. F. . Diferentes Substratos para a Produção de Mudas de Sesbania virgata. Floresta e Ambiente, v. 21, n.2, p. 224-233, 2014.

DUARTE, R. F.; SAMPAIO, R. A.; BRANDÃO JUNIOR, D. S.; SILVA, H. P.PARREIRAS, N. S.; NEVES, J. M. G. Crescimento inicial de mudas de Acacia mangium cultivadas em mantas de fibra de coco contendo substrato de lodo de esgoto. Revista Árvore v.35, n.1, p.69-76, 2011.

DUARTE, M. L.; PAIVA, H. N ; ALVES, M. O. ; FREITAS, A. F. ; MAIA, F. F. ; GOULART, L. M. L. . Crescimento e qualidade de mudas de vinhático (Platymenia foliolosa Benth.) em resposta à adubação com potássio e enxofre. Ciência Florestal, v. 25, n.1, p. 221-229, 2015. Disponível em: < http://dx.doi.org/10.5902/1980509817480> doi: 10.5902/1980509817480.

EMPRESA BRASILEIRA DE PESQUISA AGROPECUARIA - EMBRAPA. Centro Nacional de Pesquisa de Solos. Sistemas Brasileiro de classificação de solos. Rio de Janeiro-RJ. p.306, 2006.

FELFILI, M J.; FAGG, C. W.; PINTO, J. R. R. Recuperação de áreas degradadas.In: FELFILI, M. J.; SAMPAIO, J. C.; CORREIA, C. R. M. A. Conservação da Natureza e Recuperação de Áreas Degradadas na Bacia do São Francisco: treinamento e sensibilização. 1ª Edição, p. 51-62, 2008.

FERNANDES, P. A.; PESSÔA, V. L. S. O cerrado e suas atividades impactantes: Uma leitura sobre o garimpo, a mineração e a agricultura mecanizada. Observatorium: Revista Eletrônica de Geografia, v.3, n.7, p. 19-37, 2011. 
FERREIRA, W. C.;BOTELHO, S.A.; DAVIDE,A.C. ;FARIA, J. M. R.;FERREIRA, D. F. Regeneração natural como indicador de recuperação de área degradada a jusante da usina hidrelétrica de Camargos, MG. Revista Árvore, v.34, n.4, p.651660, 2010.

GANEM, R. S. Conservação da biodversidade e politicas públicas Biblioteca digital da câmara dos deputados. Série memória e análise de leis, Brasília, n.2, p.437,2011.

INSTITUTO NACIONAL DE METEOROLOGIA (INMET). Online. Disponível em: http://www.inmet.gov.br/portal/. Acesso em 20 mai. 2016.

LONDERO, E. K. ; SCHUMACHER, M. V.; RAMOS, L. O. O.; RAMIRO, G. A.; SZYMCZAK, D. A.Influência de diferentes períodos de controle e convivência de plantas daninhas em eucalipto Cerne, v. 18, n. 3, p 441-447, 2012. Disponível em < http://dx.doi.org/10.1590/S0104-77602012000300011 > doi: 10.1590/S010477602012000300011

LONGO R. M.; RIBEIRO A. I.; MELO W. J.;Caracterização física e química de áreas mineradas pela extração de cassiterita. Bragantia, v.64, n.1, p.101-107, 2005.

LORENZI, H. Árvores brasileiras: manual de identificação e cultivo de plantas arbóreas nativas do Brasil. 2.ed. Nova Odessa: Instituto Plantarum, v.1, n.2, 2002.

MARCUZZO, S. B.; ARAÚJO, M. M.; GASPARIN, E. Plantio de espécies nativas para restauração de áreas em unidades de conservação: um estudo de caso no sul do brasil. Floresta, v. 45, n. 1, p. 129 - 140, jan. / mar. 2015.

Disponível em:

http://ojs.c3sl.ufpr.br/ojs/index.php/floresta/article/view/32763/24815> doi: 10.5380/rf.v45i1.32763

MELO, L. A.; PEREIRA, G. A. ; MOREIRA, E. J. C.; DAVIDE, A. C. ; SILVA, E. V. ; TEIXEIRA, L. A. F . Crescimento de Mudas de Eucalyptus grandis e Eremanthus erythropappus sob Diferentes Formulações de Substrato. Floresta e Ambiente, v. 21, n.2,p. 234-242, 2014. Disponível em <http://dx.doi.org/10.4322/floram.2014.028> doi: 10.4322/floram.2014.028

NETO, M.J.; SANTOS, R. M.; BLINI, R.C.B.;Evidências de regeneração natural em área degradada denominada cascalheira-TRÊS LAGOAS/MS. Biodiversidade e unidade de conservação. X Fórum Ambiental da Alta Paulista, v. 10, n. 3, p. 01-13, 2014.

OLIVEIRA, M. C.; RIBEIRO, J. F. ; PASSOS, F.B. ; AQUINO, F. G. ; OLIVEIRA, F.F. ; SOUSA, S.R. . Crescimento de espécies nativas em um plantio de recuperação de Cerrado sentido restrito no Distrito Federal. Revista Brasileira de Biociências, v. 13, n.1, p. 25-32, 2015.

PILON, N. A. L. ; DURIGAN, G. . Critérios para indicação de espécies prioritárias para a restauração da vegetação de cerrado. Scientia Forestalis, v. 41, n.99, p. 
389-399, 2013.

PORTELA, R. C. Q.; SILVA, I.L.; PINÃ-RODRIGUES, F.C.M.; Crescimento inicial de mudas de Clitoria fairchildiana Howard e Peltophorum dubium (Sprenge) Taub em diferentes condições de sombreamento. Revista Ciências Florestais, v.11, n.2, p.163-170, 2001.

RIBEIRO, J. F.; WALTER, B. M. T. Fitofisionomias do bioma Cerrado. In: SANO, S. M.;ALMEIDA, S. P. (Ed.) Cerrado: ambiente e flora. Planaltina, DF: Embrapa-CPAC, cap.3, p. 87-166. 1998.

SANTOS, P. L.; ANASTÁCIO, F. R.; ARAGÃO, A. G.;AMARAL, L. A.;OLIVEIRA, A. $S$. Estabelecimento de espécies florestais nativas por meio de semeadura direta para recuperação de áreas degradadas. Revista Árvore, v. 36, n. 2, p. 237-245, 2012. Disponível em: <http://dx.doi.org/10.1590/S0100-67622012000200005> doi: $10.1590 /$ S0100-67622012000200005

NEVES, S. C.; ABREU, P. A. A.; FRAGA, L.M. S. Fisiografia. In: SILVA, A. C.; PEDREIRA, L. C. V. S. F.; ABREU, P. A. A. Serra do Espinhaço Meridional, Paisagens e Ambientes.O Lutador, Capítulo 2, 272 p. 2005. 